\title{
Integral analysis of p53 and its value as prognostic factor in sporadic colon cancer
}

\author{
Arantza Fariña Sarasqueta', Giusi Irma Forte ${ }^{1}$, Wim E Corver ${ }^{1}$, Noel F de Miranda', Dina Ruano ', Ronald van Eijk' , \\ Jan Oosting ${ }^{1}$, Rob AEM Tollenaar ${ }^{2}$, Tom van Wezel ${ }^{1}$ and Hans Morreau ${ }^{1 *}$
}

\begin{abstract}
Background: p53 (encoded by TP53) is involved in DNA damage repair, cell cycle regulation, apoptosis, aging and cellular senescence. TP53 is mutated in around 50\% of human cancers. Nevertheless, the consequences of p53 inactivation in colon cancer outcome remain unclear. Recently, a new role of p53 together with CSNK1A1 in colon cancer invasiveness has been described in mice.

Methods: By combining data on different levels of p53 inactivation, we aimed to predict p53 functionality and to determine its effects on colon cancer outcome. Moreover, survival effects of CSNK1A1 together with p53 were also studied.

Eighty-three formalin fixed paraffin embedded colon tumors were enriched for tumor cells using flow sorting, the extracted DNA was used in a custom SNP array to determine chr17p13-11 allelic state; p53 immunostaining, TP53 exons 5, 6, 7 and 8 mutations were determined in combination with mRNA expression analysis on frozen tissue.

Results: Patients with a predicted functional p53 had a better prognosis than patients with non functional p53 (Log Rank p=0.009). Expression of CSNK1A1 modified p53 survival effects. Patients with low CSNK1A1 expression and non-functional p53 had a very poor survival both in the univariate (Log Rank $p<0.001$ ) and in the multivariate survival analysis ( $\mathrm{HR}=4.74$ 95\% Cl $1.45-15.3 \mathrm{p}=0.009)$.

Conclusion: The combination of mutational, genomic, protein and downstream transcriptional activity data predicted p53 functionality which is shown to have a prognostic effect on colon cancer patients. This effect was specifically modified by CSKN1A1 expression.
\end{abstract}

Keywords: Colon cancer, p53, Prognosis, Survival, CSKN1A1

\section{Background}

During colon carcinogenesis cells accumulate several genetic and genomic aberrations that lead to uncontrolled proliferation and tumor formation [1]. A major event in the adenoma to carcinoma transition is TP53 inactivation. p53 plays a crucial role in maintaining genome stability and integrity. Upon DNA damage, the activation of p53 leads to cell cycle arrest enabling the cells to repair the damaged DNA. On the other hand, when the damage is too extensive to be repaired p53 activation can also drive the cell towards apoptosis or senescence [2]. Recently, p53 has also been implicated in tumor invasiveness [3]. In

\footnotetext{
* Correspondence: j.morreau@lumc.nl

${ }^{1}$ Department of Pathology, Leiden University Medical Centre, P.O. Box 9600

L1-Q2300 RC, Leiden, the Netherlands

Full list of author information is available at the end of the article
}

mice, the inactivation of casein kinase 1 alpha (Csnk1a1) promotes the cytoplasmatic/nuclear accumulation of $\beta$ catenin which stimulates the transcription of Wnt signaling target genes. The combined inactivation of $p 53$ and Csnk1a1 rapidly leads to tumor invasiveness in the colon of these mice.

Inactivation of TP53 is one of the most frequent events in human cancer [4]. Among others, TP53 can be inactivated by "loss of function" mutations in one allele and deletion of the remaining wild type allele or by dominant negative mutations that are able to inactivate also the wild type protein transcribed by the second unaffected allele. Either way, when p53 function is jeopardized, genomic instability and uncontrolled cell proliferation are facilitated.

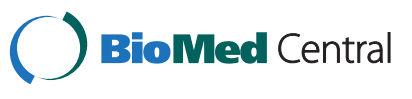


The role of p53 inactivation in colon cancer progression and prognosis has been widely studied but remains elusive notwithstanding the amount of reports addressing this subject [5-17]. Chromosomal instability (CIN) is a known prognostic factor in colon cancer [18]. Although p53 inactivation has been frequently associated with CIN, not all tumors with CIN carry an inactive p53 and vice versa [19]. More complexity is added by the recent demonstration that TP53 can behave as a haploinsufficient tumor suppressor gene. Using mouse models, Ventakachalam and coworkers demonstrated that mice carrying one functional p53 allele developed tumors but they showed however a milder phenotype than mice that lost both alleles [20]. Moreover, several reports described the TP53 gene dosage effect on expression of target genes [21,22].

Recent developments in genomic copy number analysis have shown to more accurately study the measure of chromosomal structural and numeric aberrations [23]. The development of the lesser allele intensity ratio (LAIR) algorithm that integrates the DNA index in the analysis of copy number data gives a real measure of the chromosomal alterations and allows the study of gene dosage effects in tumors.

Given the complexity of the p53 network, the several ways of p53 inactivation, and the recently described role of p53 in cancer invasiveness in mice, we studied in detail different levels of p53 inactivation in human colon cancer taking into account the allelic state of the locus on the short arm of chromosome 17, gene mutation state, protein expression levels, downstream target gene expression and determine the prognostic impact in colon cancer patients. Moreover, interactions with the recently described CSNK1A1 expression and the impact on disease outcome were also explored.

\section{Patients and methods Patients}

Inclusion criteria for this study were sporadic colorectal cancers in stage I, II and III. Stage IV patients were not included because the disease is metastasized and therefore the therapy has a palliative character instead of a curative character.

Thus, eighty-three sporadic colorectal cancer patients diagnosed as stage I, II or III at the Leiden University Medical Centre between 1991 and 2005 were selected for the present study. Microsatellite instability of these cancers had been determined for this group, as described elsewhere [24]. The use of clinical material was approved by the medical ethical board of the Leiden University Medical Centre

Tumors were classified according to the WHO classification of tumors of the digestive system [25].

\section{Methods}

Determination of p53 functionality

Tissue preparation for multiparameter flow cytometry and sorting

Tumor and stromal cells were sorted from FFPE tissue blocks using the FACS ARIA I (BD Biosciences, San Jose, CA, USA) based on vimentin, keratin expression and DNA content as previously described by Corver et al. [26,27]. DNA index (DI) defined as the ratio between the median $G_{0} / G_{1}$ keratin positive epithelial fraction and the median $G_{O} / G_{1}$ vimentin stromal fraction, was calculated using a remote link between Winlist and ModFit (Verity Software House) for each sample. Whenever, more than one keratin positive population was seen, it was independently sorted. DI was categorized as $\mathrm{DI}<0.95 ; \mathrm{DI}=0.95-1.05 ; \mathrm{DI}=1.06-1.4 ; \mathrm{DI}=1.41-1.95$ and $\mathrm{DI}>1.95$.

DNA was purified from sorted cells after an overnight proteinase $\mathrm{K}$ digestion using the Nucleospin Tissue kit (Macherey Nagel, Düren, Germany) following manufacturer's instructions.

\section{SNP array hybridization for allelic state determination}

A custom Golden Gate genotyping panel with 384 SNPs was designed using the Assay Design Tool (Illumina Inc. San Diego, CA, USA). The panel contains SNPs mapping to the following chromosomes: 1q21-25, 8q22-24, 13q12-34, 17p13-11 (the TP53 locus), 18q12-22, 20q1113 , all of which are associated with tumor progression in the colorectum [28]. SNPs on chromosome 2 served as controls. Paired samples were analysed in the Golden Gate assay as described [29] and hybridized to Sentrix Array Matrix with 384 bead types. SNP arrays were analysed in the BeadarraySNP package. The data generated was analyzed with the LAIR algorithm [23] that integrates the DNA index into the analysis. Four observers determined LAIR scores independently (AFS, WEC, GIF and TVW). FISH validated the 3 of the 83 samples that showed discordance $(3.6 \%)$ between the observers.

We differentiated the following allelic states:

1) Retention with genotype $A B ; 2)$ Loss of heterozygosity $(\mathrm{LOH})$, genotype $\mathrm{A} ; 3)$ copy neutral $\mathrm{LOH}(\mathrm{cnLOH})$, genotype AA; 4) amplified $\mathrm{LOH}(\mathrm{aLOH})$ genotypes AAA or AAAA etc.; 5) allelic imbalance (AI) or genotypes AAB, AAABB etc.; 6) balanced amplification (BA), genotypes $\mathrm{AABB}, \mathrm{AAABBB}$ etc.; 7) multiclonal tumors (identified through flow cytometry, see Figure $1 \mathrm{a}$ and b) [23].

\section{FISH}

To confirm the copy number results obtained with the SNP array, FISH in nuclei obtained from FFPE material of seven patients was performed. First, 2mm. punches (Beecher Instruments, Silver Springs, MD, USA) of 


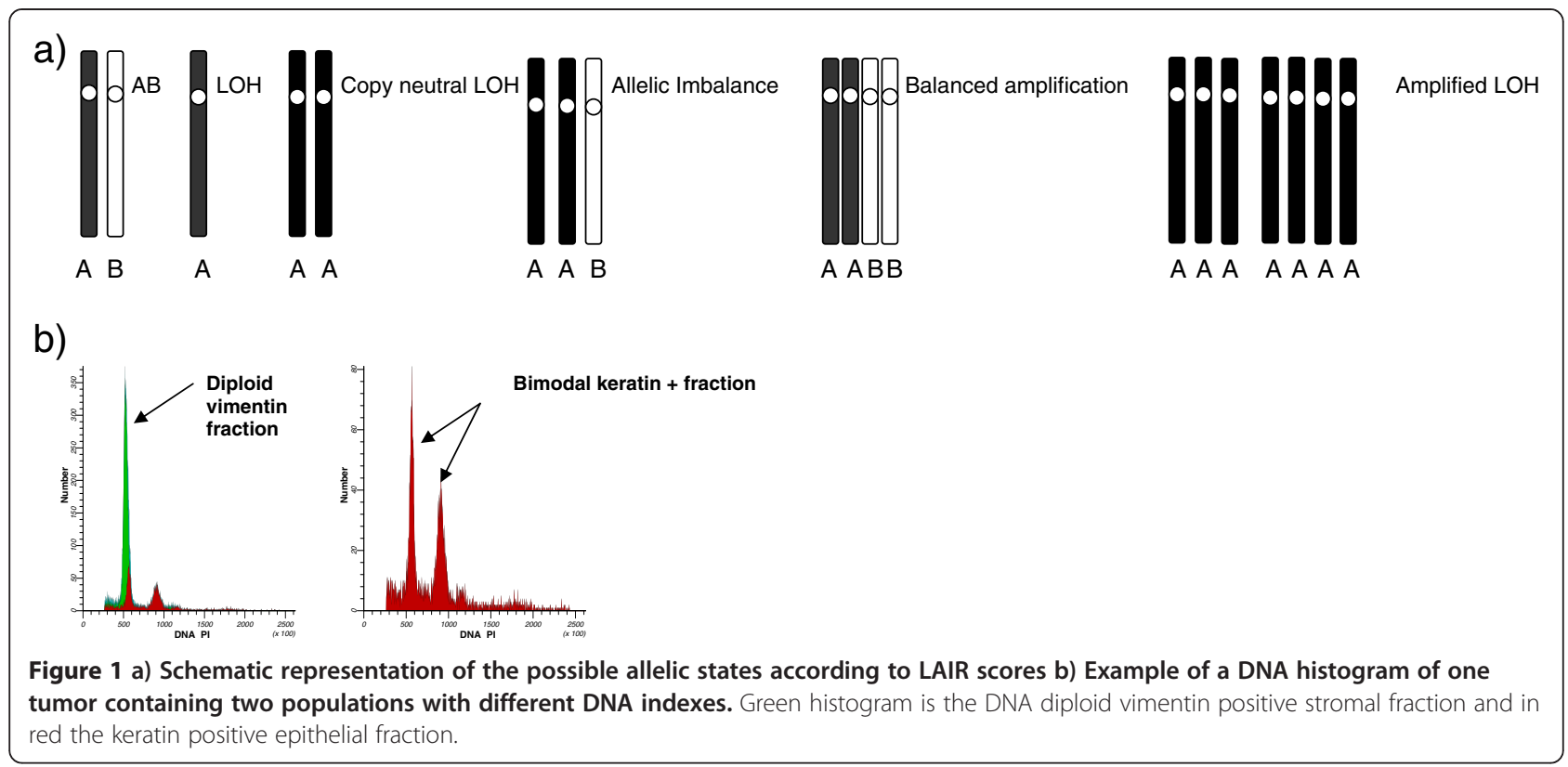

selected tumor areas were embedded in blanco acceptor paraffin blocks. Subsequently, $50 \mu \mathrm{M}$ slices were obtained, deparaffinized and rehydrated. Antigen retrieval was performed by high pressure cooking in Tris-EDTA $\mathrm{pH}=9$. After incubation for one hour at $37^{\circ} \mathrm{C}$ with RNAse, samples were digested with $0.5 \%$ pepsin $\mathrm{pH}=2$ at $37^{\circ} \mathrm{C}$ for 30 minutes. The obtained nuclei were then washed and resuspended in methanol: acetic acid in a 3 to 1 proportion. Thereafter nuclei were spun onto clean glasses and hybridization with Vysis ${ }^{\circ}$ TP53/CEP17 FISH probe kit (Abbot Molecular, IL, USA) was allowed overnight at $37^{\circ} \mathrm{C}$. After washing, samples were mounted with Vectashield $^{\oplus}$ mounting medium containing DAPI (Vector Laboratories Inc., Burlingame, CA, USA) and nuclei were evaluated under the fluorescence microscope.

Seven tumors were tested for which enough material was available and with different allelic states of chr.17p according to the SNP array analysis.

\section{p53 IHC staining}

Tissue microarrays (TMA) of these tumors were prepared by punching three representative tumor areas selected by a pathologist (HM) on HE stained slides and arraying them on a recipient paraffin block (Beecher Instruments, Silver Springs, MD, USA). Five $\mu \mathrm{M}$ slices were then cut. Heat induced antigen retrieval (HIAR) was performed as described elsewhere [28] and staining was carried out with the mouse antihuman monoclonal antibodies directed against p53 (clone D0-7, 1:1000 dilution) (Lab Vision NeoMarkers, Fremont, CA, USA).

p53 was scored in four different categories based on any level of nuclear staining, like previously described
[30] by an experienced pathologist (HM) and a pathology resident (AFS): completely negative; 1 - $25 \%$ positive nuclei (indicative of a wild type state); $25-75 \%$ positive nuclei and $>75 \%$ positive nuclei. For analysis purposes, the last two categories were fused in only one category; more than $25 \%$ positive cells (indicative of a mutated gene).

\section{TP53 mutation analysis}

Tumor DNA available from 40 patients was isolated from enriched tumor areas containing at least 50\% tumor cells, as described above. Four different PCRs were performed for amplification of exons 5, 6, 7 and 8 of the TP53 gene. Ten nanograms DNA was used for each PCR using primers already published modified for SYBRgreen ${ }^{\circ}$ detection [31]. Subsequently, PCR products were purified using Qiagen's MinElute ${ }^{\mathrm{rm}} 96$ UF PCR Purification Kit (Qiagen Sciences, Germantown, MD, USA) and reactions were sequenced using the MI13 forward and reverse primers. Analysis was performed using the Mutation Surveyor $3.97^{\circ}$ sequence analysis and assembly software (SoftGenetics LLC, Stage College, PA, USA).

\section{mRNA expression arrays}

Fresh frozen tissue of fifty-seven patients was available for mRNA expression analysis. mRNA was isolated, labeled and hybridized to customized Agendia $44 \mathrm{~K}$ oligonucleotide array as described elsewhere [24].

\section{Statistical analysis}

Associations between categorical variables were studied by $\chi^{2}$ and Fischer exact test. Univariate survival analysis was performed by Kaplan Meier analysis and differences 
between survival curves were studied by Log Rank analysis. Cox Proportional Hazard Model performed multivariate survival analysis. Cancer Specific Survival was defined as the time between curative intended surgery and death by cancer related causes [32]. Results were considered significant when $\mathrm{p}$ value $<0.05$. All tested were two tailed. All of the analyses mentioned above were performed using SPSSv16 package for Windows (Chicago, IL, USA)

Statistical analysis of the mRNA expression data was done using the LIMMA (Linear Modelling for Microarray Analysis) framework in Bioconductor [33].

The expression of the 35 genes reported by Yoon et al. [22] as genes which expression is TP53 gene dosage dependent was analyzed in relation with p53 functional state. Furthermore, expression levels of three probes targeting different locations in the 3'UTR of the CSNK1A1 gene (NM_001025105.1 transcript) were independently analyzed.

Finally, expression levels of eight genes reported by Elyada et al. [3] as involved in murine tumor invasiveness were also analyzed.

\section{Results}

Patients' description

Patients' characteristics are shown in Table 1. Summarized, $54 \%$ of the patients were female, $63 \%$ of the tumors were right sided (i.e. tumors located in the colon from the cecum until the splenic flexure) and 37\% left sided. $4 \%$ of the patients had stage I disease at diagnosis, $61 \%$ stage II and $35 \%$ stage III. Twenty-seven tumors were MSI-H (33\%), whereas 55 (67\%) were MSS tumors.

Median follow up was 69 months (range 2 - 199). At the end of the follow up, $41 \%$ of the patients were alive, $24 \%$ of the patients had died because of cancer related causes and 30\% died because of non-cancer related causes.

\section{Allelic state}

All samples were flow cell sorted as previously described and analyzed with a custom SNP array comprising several chromosomal regions previously reported to be implicated in colorectal cancer progression [28]. In the present study we have focused on the allelic state of the TP53 locus on chromosome 17p13-11 Of the 83 tumors analyzed, $47 \%$ were classified as normal with genotype $\mathrm{AB}, 11 \%$ as $\mathrm{LOH}$ (genotype $\mathrm{A}), 13 \%$ as $\mathrm{cnLOH}$ (genotype AA), $8 \%$ as aLOH (genotype AAA/AAAA) and $4 \%$ as $\mathrm{AI}$ (genotype $\mathrm{AAB} / \mathrm{AAABB}$ ). Note also that $17 \%$ of the patients showed multiple cancer populations by flow cytometry (results shown in Table 1). No balanced amplifications were seen in the monoclonal series. FISH analysis was used to confirm the chromosome 17 LAIR scores for seven samples (Figure 2).
Table 1 Patients' characteristics

\begin{tabular}{|c|c|}
\hline Characteristics & Total N (\%) \\
\hline \multicolumn{2}{|l|}{ Age } \\
\hline $50-59$ & $14(17)$ \\
\hline $60-69$ & $27(33)$ \\
\hline 70-79 & $24(30)$ \\
\hline 80-89 & $16(20)$ \\
\hline \multicolumn{2}{|l|}{ Gender } \\
\hline Male & $34(41)$ \\
\hline Female & $45(54)$ \\
\hline \multicolumn{2}{|l|}{ Tumor Location } \\
\hline Right & $52(63)$ \\
\hline Left & $31(37)$ \\
\hline \multicolumn{2}{|l|}{ Stage } \\
\hline | and || & $54(65)$ \\
\hline III & $29(35)$ \\
\hline \multicolumn{2}{|l|}{ MMR status } \\
\hline MSS & $55(67)$ \\
\hline MSI-H & $27(33)$ \\
\hline \multicolumn{2}{|l|}{ Chr.17p allelic state } \\
\hline$A B$ & $39(47)$ \\
\hline $\mathrm{LOH}$ & $9(11)$ \\
\hline $\mathrm{CNLOH}$ & $11(13)$ \\
\hline $\mathrm{ALOH}$ & 7 (8) \\
\hline $\mathrm{Al}$ & $3(4)$ \\
\hline Multiple clones & $14(17)$ \\
\hline \multicolumn{2}{|l|}{ DNA index } \\
\hline $0.95-1.05$ & $35(46)$ \\
\hline $1.06-1.40$ & $10(13)$ \\
\hline $1.41-1.95$ & $31(41)$ \\
\hline \multicolumn{2}{|l|}{ TP53 } \\
\hline wt & $22(55)$ \\
\hline mut & $18(45)$ \\
\hline \multicolumn{2}{|l|}{ IHC p53 } \\
\hline $0 \%$ & $10(13)$ \\
\hline$>0 \%-\leq 25 \%$ & $35(46)$ \\
\hline$>25 \%$ & $31(41)$ \\
\hline Median Follow up in months (range) & $68.84(2-199)$ \\
\hline
\end{tabular}

\section{Predicted p53 functionality}

We predicted the functionality of p53 (hereafter called functionality) for each sample (see Additional file 1: Table S1) by combining data from the TP53 locus allelic state, mutation data and protein expression levels. Overall, the three parameters were mostly in agreement with each other, except for 6 out of 57 patients where there was one discordance between mutation state, protein expression and/or allelic state. To call p53 non functional, 


\section{Sample 1 DNA index $=1.1$}

a)

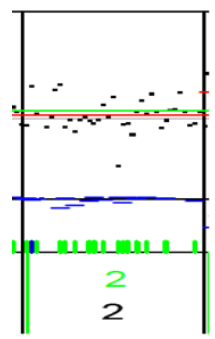

LAIR chr 2: AB

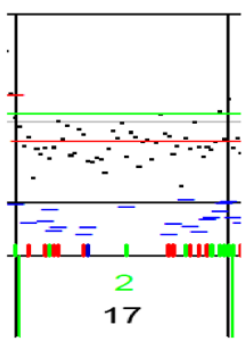

LAIR chr.17: A b)

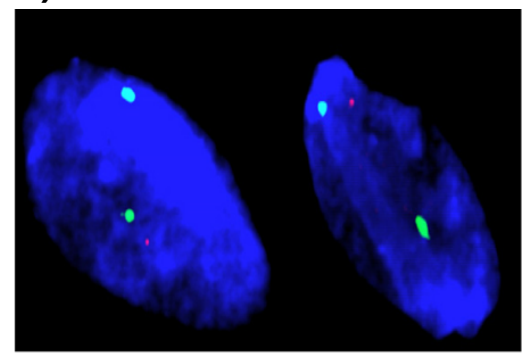

FISH: two centromeres and one p53 copy

Sample 2 DNA index $=2.3$

a)

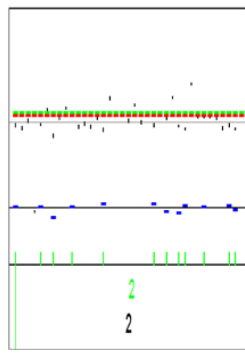

LAIR chr. 2: AABB

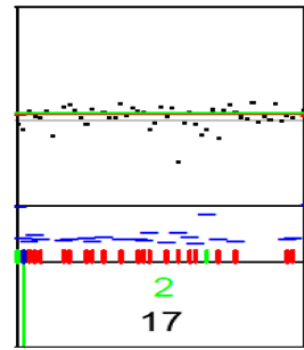

LAIR chr.17 AAAA b)

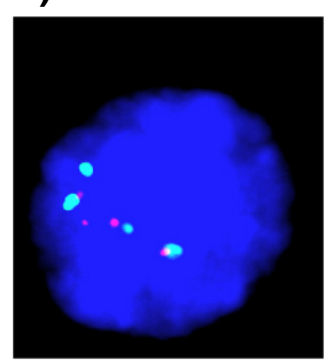

FISH: four centromeres and four p53 copies

Figure 2 Results of a) SNP array on reference chromosome and chr.17p b) FISH on Chr. 17 (the green signal corresponds to the centromere probe and the red signal to the $\mathrm{p} 53$ probe).

at least two parameters should point in that direction. Mutation state or IHC expression level weighted more in decision making whenever one of the three parameters was not available. Associations between p53 functionality and the different variables are shown in Table 2. In summary, the majority of tumors with a functional p53 (78\%) lacked TP53 mutations $(\mathrm{p}=0.01)$ and all showed between $0-25 \%$ positive stained cells using immunohistochemistry $(\mathrm{p}<0.001) .78 \%$ of the tumors with functional $\mathrm{p} 53$ had a near diploid DNA index raging from $0.95-1.05$ whereas $63 \%$ of the non functional p53 samples was highly aneuploid with DNA indexes ranging 1.41 - $1.95(\mathrm{p}<0.001)$. Samples with functional p53 showed significantly more retention of the p53 locus (genotype $\mathrm{AB}$ ) as compared to the group with either aLOH (AAA/AAAA) $(\mathrm{p}=0.005), \mathrm{cnLOH}(\mathrm{AA})(\mathrm{p}<0.001)$ and cases with multiclonallity $(p=0.006)$. Moreover, the frequency of functional p53 was increased in tumors with $\mathrm{LOH}$ than with $\mathrm{cnLOH}(\mathrm{p}=0.01)$. Furthermore, tumors with a functional p53 were significantly overrepresented in the group of right-sided tumors $(p=0.035)$. Of the tumors with non-functional p53, eighty-six percent showed the MSS phenotype $(\mathrm{p}=0.009)$.

To corroborate the classification in functional and non-functional p53 groups, we compared p53 target gene expression levels between these two groups. We selected genes for which expression was previously shown to be p53 gene dosage dependent by Yoon et al. [22]. Eight genes differently expressed between both groups were identified (Table 3). As expected, known p53 targets like $M D M 2$ and $C D K N 1 A$ were significantly higher expressed in the p53 functional group than in the non functional group $(\mathrm{p}=0.0025$ and $\mathrm{p}=0.0013$ respectively). Genes higher expressed in the non functional group were involved in many processes such as cell proliferation (PRKCZ), protein ubiquitination (SIAH1), metabolism (HMGCS1) and cell differentiation (PRKCZ, PDE6A).

\section{Survival analysis}

In a univariate survival analysis, p53 functionality was prognostic; patients with functional p53 had a better cancer specific survival than patients with non-functional p53 (Log rank $\mathrm{p}=0.009$ ) (Figure 3).

In our cohort, patients with MSI-H tumors are slightly more frequent than expected from epidemiological studies (33\% vs. 18\% expected), nevertheless MMR status did not influence survival (data not shown) nor the effects of p53 functionality on survival.

Recently, the role of $p 53$ and Csnk1a1 inactivation in tumor invasiveness in mice has been demonstrated [3]. 
Table 2 Associations between clinicopathological variables and p53 functionality

\begin{tabular}{|c|c|c|c|}
\hline & p53 non functional $N(\%)$ & p53 functional N (\%) & $p$ value \\
\hline \multicolumn{4}{|l|}{ TP53 mutational status } \\
\hline wt & 7 (33) & $14(78)$ & 0.01 \\
\hline mut & $14(67)$ & $4(22)$ & \\
\hline \multicolumn{4}{|l|}{ P53 IHC } \\
\hline 0 & $3(11)$ & $7(24)$ & $<0.001 \#$ \\
\hline $0-\leq 25 \%$ & $1(3)$ & $22(76)$ & \\
\hline$>25 \%$ & $24(86)$ & $0(0)$ & \\
\hline \multicolumn{4}{|l|}{ Chr. 17 p status } \\
\hline$A B$ & $5(18)$ & $22(76)$ & $<0.001^{*}$ \\
\hline $\mathrm{LOH}$ & $2(7)$ & $4(14)$ & \\
\hline Copy neutral LOH & $9(32)$ & $0(0)$ & \\
\hline Amplified LOH & $5(18)$ & $1(3)$ & \\
\hline Allelic Imbalance & $1(4)$ & $0(0)$ & \\
\hline Two clones & $6(21)$ & $2(7)$ & \\
\hline \multicolumn{4}{|l|}{ Age category } \\
\hline $50-59$ & $4(14)$ & $6(22)$ & NS \\
\hline $60-69$ & $10(36)$ & $9(32)$ & \\
\hline $70-79$ & $10(36)$ & $9(32)$ & \\
\hline $80-89$ & $4(14)$ & $4(14)$ & \\
\hline \multicolumn{4}{|l|}{ DNA index } \\
\hline $0.95-1.05$ & $6(22)$ & $21(78)$ & $<0.0019$ \\
\hline $1.06-1.4$ & $4(15)$ & $3(11)$ & \\
\hline $1.41-1.95$ & $17(63)$ & $3(11)$ & \\
\hline \multicolumn{4}{|l|}{ MMR status } \\
\hline MSI & $4(14)$ & $14(50)$ & 0.009 \\
\hline MSS & $24(86)$ & $14(50)$ & \\
\hline \multicolumn{4}{|l|}{ Gender } \\
\hline Male & $12(43)$ & $18(62)$ & NS \\
\hline Female & $16(57)$ & $11(38)$ & \\
\hline \multicolumn{4}{|l|}{ Tumor Location } \\
\hline Right & $10(36)$ & $19(66)$ & 0.035 \\
\hline Left & $18(64)$ & $10(34)$ & \\
\hline \multicolumn{4}{|l|}{ Stage } \\
\hline I and || & $14(50)$ & $22(76)$ & 0.06 \\
\hline III & $14(50)$ & $7(24)$ & \\
\hline Median Follow up in months & 66.75 & 89.77 & 0.4 \\
\hline
\end{tabular}

${ }^{*} x^{2}$ test allelic status $A B$ vs. $L O H p=0.58 ; A B$ vs. $C N L O H ~ p<0.001 ; A B$ vs. ALOH $p=0.005 ; A B$ vs. two clones $p=0.006$

LOH vs. CNLOH $p=0.01 ; \mathrm{LOH}$ vs. ALOH $p=0.24 ; \mathrm{LOH}$ vs. two clones $p=0.28$.

ALOH vs. CNLOH $p=0.43$; Amp LOH vs. two clones $p=1$.

CNLOH vs. two clones $p=0.48$.

$\# X^{2}$ test $\mathrm{p} 53 \mathrm{IHC} 0$ vs. $0-25 \% \mathrm{p}=0.07 ; \mathbf{0}$ vs. $>\mathbf{2 5} \% \mathbf{p}<\mathbf{0 . 0 0 1 ;} \mathbf{0}-\mathbf{2 5} \%$ vs. $>\mathbf{2 5 \%} \mathbf{p}=\mathbf{0 . 0 0 1}$.

凡 $\mathrm{X}^{2}$ test DNA index $0.95-1.05$ vs. $1.06-1.4 \mathrm{p}=0.16 ; \mathbf{0 . 9 5}-\mathbf{1 . 0 5}$ vs. $\mathbf{1 . 4 1} \mathbf{1} \mathbf{1 . 9 5} \mathbf{p}<\mathbf{0 . 0 0 1} ; 1.06-1.40$ vs. $1.41-1.95 \mathrm{p}=0.29$.

We analyzed whether the expression levels of CSNK1A1 modulate $\mathrm{p} 53$ effects in disease outcome. Patients were divided according to the expression level. In the group with high CSNK1A1 expression the expression level of the three probes analyzed (A_23_P213551; A_24_P183292; A_24_P251899) exceeded the median value for that specific probe while in cases with low CNSK1A1 expression the value was lower than the median. 
Table 3 List of genes differentially expressed between functional p53 and non functional p53 groups

\begin{tabular}{|c|c|c|c|}
\hline $\begin{array}{l}\text { Gene } \\
\text { name }\end{array}$ & $\begin{array}{c}\text { Chr. } \\
\text { position }\end{array}$ & Gene description & $\begin{array}{l}\text { p-value, p53 functional vs. } \\
\text { p53 non functional }\end{array}$ \\
\hline \multirow[t]{2}{*}{ PRKCZ } & $\begin{array}{l}1 \mathrm{p} 36.33- \\
\text { p36.2 }\end{array}$ & $\begin{array}{l}\text { Serine threonine kinase involved in several processes such as proliferation, differentiation } \\
\text { and secretion. }\end{array}$ & 4.95E-04 \\
\hline & & & $\uparrow$ non functional \\
\hline \multirow[t]{2}{*}{ LMO3 } & \multirow[t]{2}{*}{$12 \mathrm{p} 12.3$} & \multirow{2}{*}{$\begin{array}{l}\text { Lim domain only } 3 \text { (rhombotin like 2). Expression of LMO-3 represses p53 mediated mRNA } \\
\text { expression of target genes. }\end{array}$} & $1.2 \mathrm{E}-02$ \\
\hline & & & $\uparrow n o n$ functional \\
\hline CDKN1A & $6 \mathrm{p} 21.2$ & Cyclin dependent kinase inhibitor. Causes cell cycle arrest in the presence of DNA damage. & $1.3 \mathrm{E}-02 \uparrow f u n c t i o n a l$ \\
\hline \multirow[t]{2}{*}{ PDE6A } & \multirow{2}{*}{$\begin{array}{l}5 \mathrm{q} 31.2- \\
\mathrm{q} 34\end{array}$} & \multirow[t]{2}{*}{ Phosphodiesterase 6A, cGMP-specific, rod, alpha } & 7.47E-02 \\
\hline & & & $\uparrow n o n$ functional \\
\hline \multirow[t]{2}{*}{ SIAH1 } & \multirow[t]{2}{*}{$16 q 12$} & \multirow{2}{*}{$\begin{array}{l}\text { Seven in absentia homolog 1. Involved in ubiquitination and proteosome related } \\
\text { degradation of specific proteins like beta catenin. }\end{array}$} & 2.60E-02 \\
\hline & & & $\uparrow n o n$ functional \\
\hline \multirow[t]{2}{*}{ TPD52L2 } & \multirow{2}{*}{$\begin{array}{l}20 q 13.2- \\
q 13.3\end{array}$} & \multirow[t]{2}{*}{ Tumor protein D52 like 2. Expressed in childhood leukemia and testes. } & 4.65E-02 \\
\hline & & & $\uparrow n o n$ functional \\
\hline \multirow[t]{2}{*}{ MDM2 } & \multirow{2}{*}{$\begin{array}{l}12 q 14.3- \\
q 15\end{array}$} & \multirow[t]{2}{*}{ MDM2 p53 binding protein homolog (Mouse) } & $1.25 \mathrm{E}-02$ \\
\hline & & & $\uparrow$ functional \\
\hline \multirow[t]{2}{*}{ HMGCS1 } & $5 p 14-p 13$ & 3-hydroxy 3-methylglutaryl-CoA synthase I & $1 \mathrm{E}-01$ \\
\hline & & & $\uparrow$ functional \\
\hline
\end{tabular}

All p-values are corrected for multiple tests.

The values of the three probes correlated significantly with each other (Pearson's correlation coefficient $=0.94$ $\mathrm{p}<0.001$ between A_23_P213551 and A_24_P251899, $0.747 \mathrm{p}<0.001$ between A_23_P213551 and A_24_P183292 and finally $0.743 \mathrm{p}<0.001$ between A_24_P183292 and A_24_P251899) (Figure 4). The three probes had the same detrimental effect on survival in a univariate analysis with different significant $\mathrm{p}$ values (data not shown). We selected the probe (A_24_P183292) with the most significant results ( $\log$ rank $\mathrm{p}=0.003)$ for further analyses.

CSNK1A1 expression significantly altered the effect of p53 in survival as shown in Figure 5. CSNK1A1 had no influence on survival when p53 is functional, however, when p53 was non-functional, CSNK1A1 expression influenced disease outcome dramatically. Patients with low CSNK1A1 expression had a very poor prognosis compared with patients with high CSNK1A1 expression (Log rank $\mathrm{p}=0.007$ ) (Figure 5).

Subsequently, we compared the patients with non functional p53 and low CSNK1A1 expression with the rest of patients (i.e. non functional p53 and high CSNK1A1 expression or functional p53 with high or low CSNK1A1 expression). Survival in patients with both genes affected was decreased compared to patients with one of both

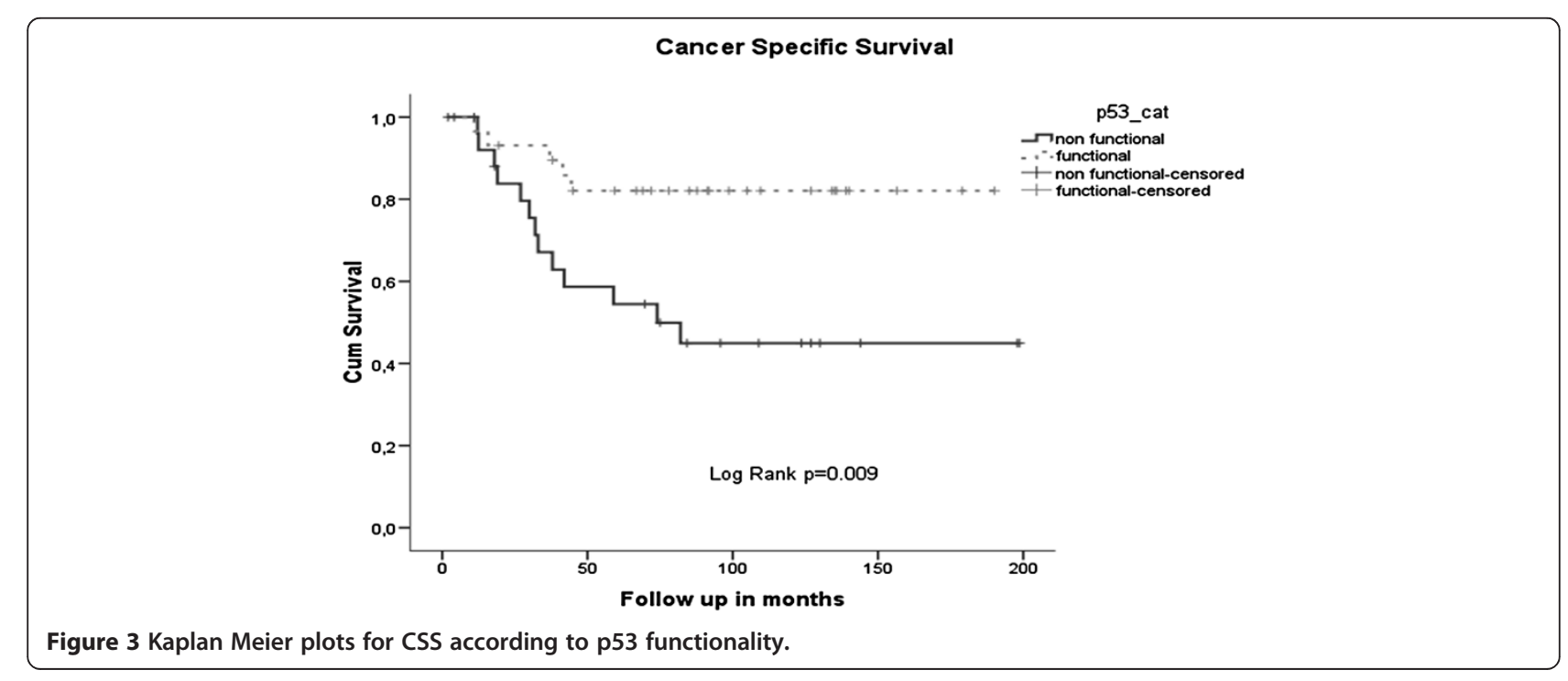




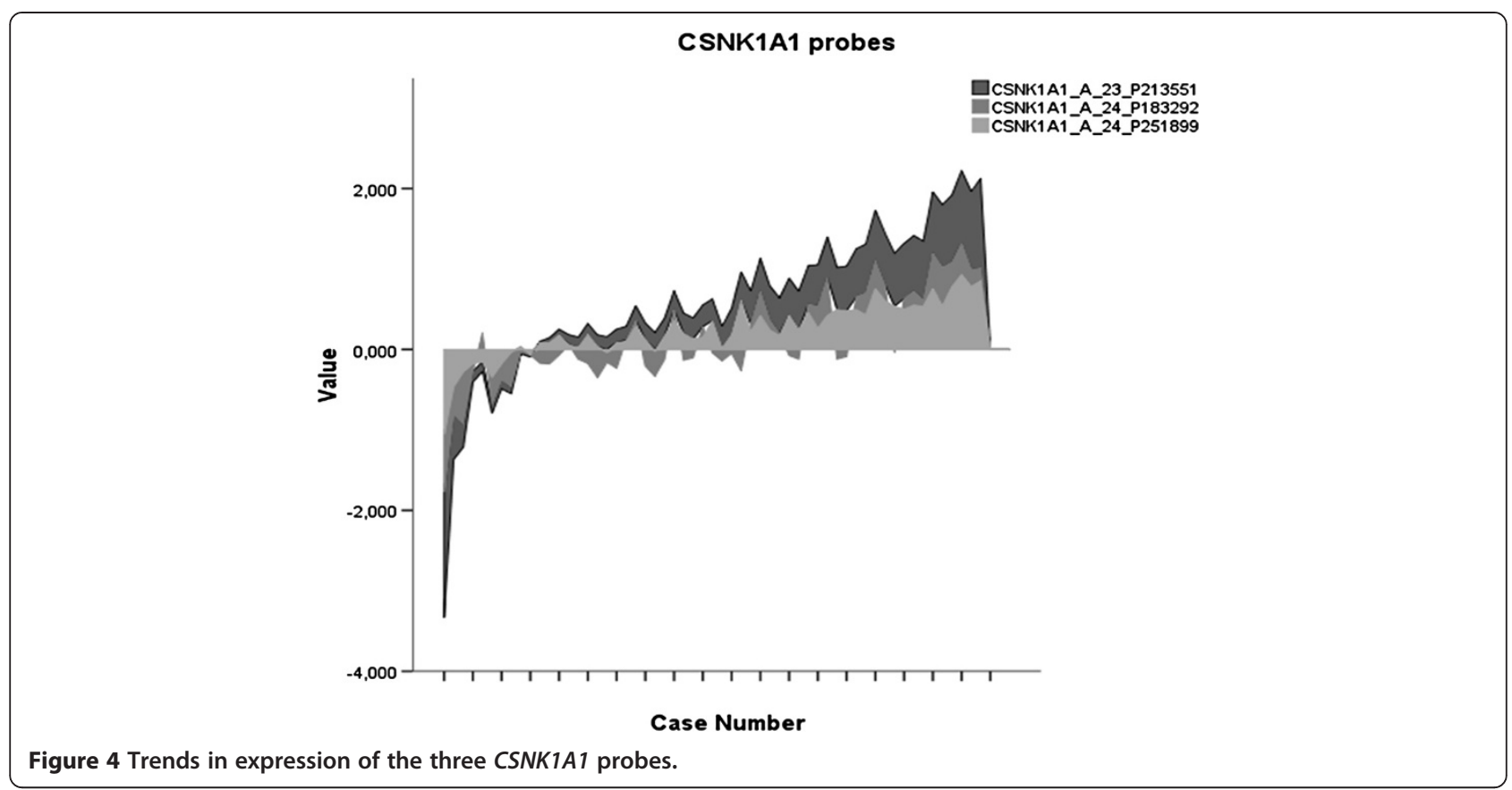

genes active (Figure 6) (Log rank $\mathrm{p}<0.001)$. Moreover, this detrimental effect on disease outcome was significant in a multivariate model including tumor stage, gender, tumor ocation and MMR status in the model $(\mathrm{HR}=4.7495 \% \mathrm{CI}$ 1.47-15.34 $\mathrm{p}=0.009$ ) (Table 4).

\section{Expression of invasiveness genes}

Elyada et al. reported up regulation of eight genes in p53 and Csnk1a1 double knockout mice and their involvement in murine tumor invasiveness [3]. We analysed their expression in our series. Two genes, mainly PLAT (plasminogen activator tissue) and PNLPRP1 (pancreatic lipase related protein 1) were significantly differently expressed between the two groups of patients; the group with low CSKN1A1 expression and non-functional p53 vs. the remaining group (with functional p53 and high or low CSKN1A1 expression and non functional p53 and high CSNK1A1 expression). PLAT was upregulated in the latter group $(\mathrm{p}=0.009)$ whereas PNLPRP1 was higher expressed in the non-functional p53 and low CSNK1A1 expression $(p=0.009)$.

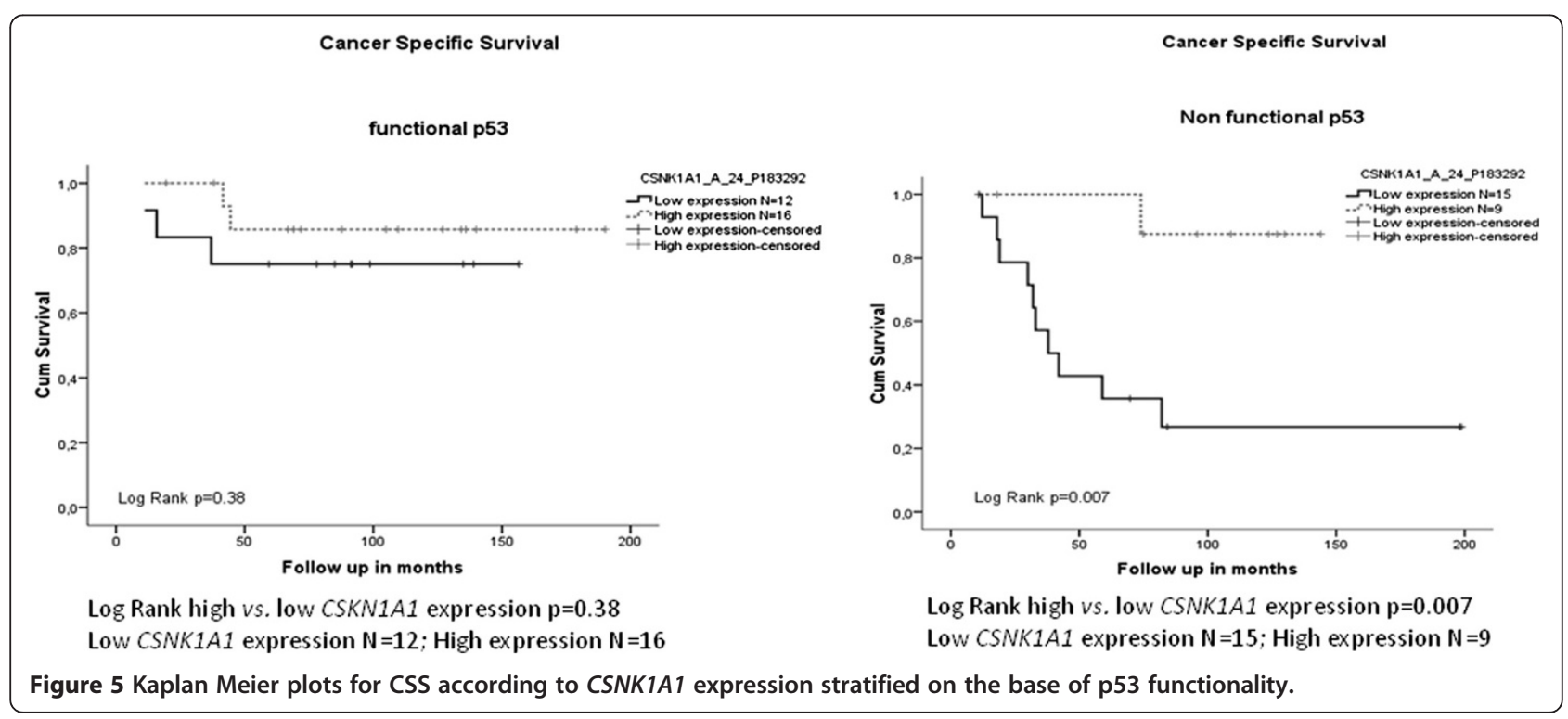




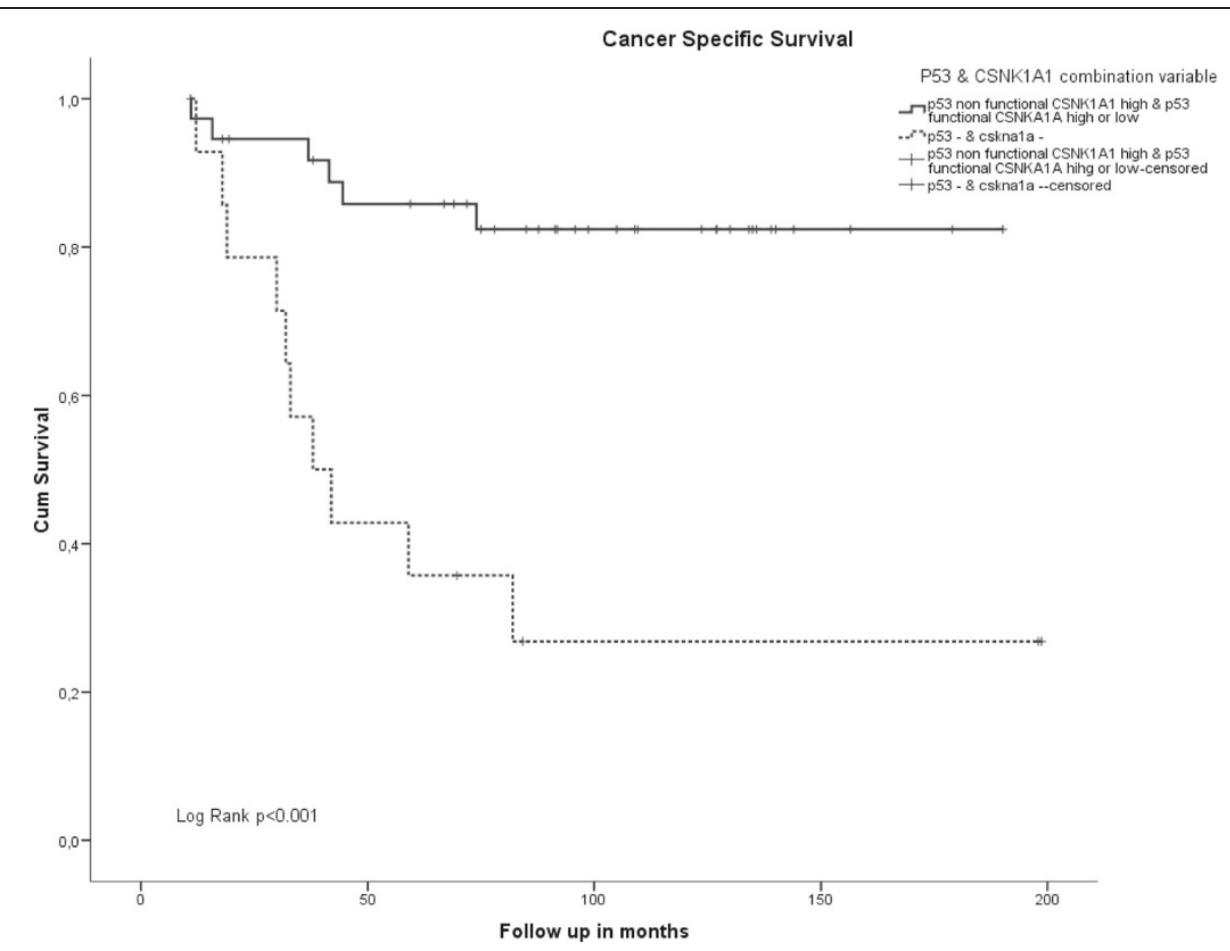

Figure 6 Kaplan Meier for CSS according to $\mathrm{p} 53$ and CSNK1A1 combination variable.

\section{Discussion}

TP53 is a transcription factor with important functions in cellular apoptosis, senescence, DNA damage repair, autophagy, aging and glycolysis [34-36]. Therefore, it is a strategic target for inactivation in cancer cells; indeed, somatic mutations are found in approximately $50 \%$ of all tumors [4]. However, the consequences of p53 inactivation in disease outcome in colon cancer remain controversial and subject to discussion. These inconclusive result could in part be explained by the combination of differences in the techniques used to assess p53 alterations (IHC or mutation analysis), and the many possible ways of p53 inactivation (deletion and dominant negative, loss or gain of function mutations).

Table 4 Cox Proportional Hazards Model: multivariate survival analysis

\begin{tabular}{|c|c|c|c|}
\hline Variables & HR & $95 \% \mathrm{Cl}$ & $\mathrm{p}$ value \\
\hline \multicolumn{4}{|l|}{ p53 \& CSNK1A1 } \\
\hline p53 - \& CSNK1A1 + and p53+ \& CSNKA1A +/- & Referent & & \\
\hline p53 - CSNK1A1 - & 4.74 & $1.47-15.34$ & $0.009 *$ \\
\hline \multicolumn{4}{|l|}{ Tumor stage } \\
\hline$|\&| \mid$ & Referent & & \\
\hline III & 3.48 & $1.08-11.2$ & $0.037^{*}$ \\
\hline \multicolumn{4}{|l|}{ Tumor location } \\
\hline Right & Referent & & \\
\hline Left & 0.92 & $0.32-2.67$ & 0.58 \\
\hline \multicolumn{4}{|l|}{ Gender } \\
\hline Male & 0.92 & $0.32-2.97$ & 0.88 \\
\hline Female & Referent & & \\
\hline \multicolumn{4}{|l|}{ MMR state } \\
\hline MSS & 0.43 & $0.097-1.91$ & 0.27 \\
\hline MSI & Referent & & \\
\hline
\end{tabular}

* Statistically significant results. 
We studied TP53 using several approaches; first we determined tumor ploidy and TP53 locus allelic state. Next, we assessed TP53 mutation state and protein expression by IHC. By integrating these data we could predict p53 functionality. The classification in functional and nonfunctional p53 was supported by the significant differences in target gene expression between these two groups. Thus, with this approach complete information on the gene was obtained allowing a more reliable classification than solely by mutation analysis or immunohistochemistry.

As it could be expected based on the functions of p53, tumors with a non-functional p53 were highly aneuploid. Moreover, the prognosis for patients with these tumors was worse compared to the group with functional p53.

We have also shown that p53 can indeed behave as a haploinsufficient tumor suppressor gene as demonstrated in mouse models [20]. We accurately assessed the TP53 genotypes by combining the allelic state at the TP53 locus using SNP arrays, combined with TP53 mutation analyses. In our cohort there were a few cases with $\mathrm{LOH}$ at the TP53 locus but without mutations in exons 5, 6, 7 and 8 and without positive immunostaining. Moreover, the tumors had a near-diploid genome and were associated with a good disease outcome as compared with other patients (Supplementary data figure 1). Our finding supports the observation that p53 +/- mice did develop tumors but show a milder phenotype than p53-/- mice [20].

Recently, in mice Csnkla1 or CKI $\alpha$ expression has been implicated in colon cancer invasiveness and cell transformation in the gut [3]. CSNK1A1 is a serine/ threonine kinase that phosphorylates $\beta$-catenin to target it for destruction [37]. In a mouse model, ablation of Csnkla1 caused the accumulation of $\beta$-catenin in the cytoplasm and nucleus activating many Wnt target genes although no tumor formation was observed. Instead, senescence was induced in these cells pointing to a possible role of p53 in tumor inhibition. Indeed, the authors found that inactivation of both Csnk1a1 and $p 53$ rendered the cell malignant and rapidly invasive [3]. Likewise, in the present cohort of patients, we have identified CSNK1A1 as a dramatic modifier of p53 effects on survival. High CSNK1A1 expression partly counteracts the negative effects of a non functional p53. Accordingly, low CSNK1A1 expression and non functional p53 was equal to a very poor prognosis with a median survival time of 3 years and a 5 -year survival of only $35 \%$, which is extremely poor for early stage disease. Furthermore, this negative effect on survival was independent of disease stage, gender, tumor location and mismatch repair state, as shown in the multivariate analysis.

The exact mechanism behind this poor survival is unknown; Elyada et al. showed that expression of certain genes was upregulated in the double knockout mice (p53-/- and Csnk1a1-/-) as compared with the only
Csnk1a1-/- mice. Some of these genes were involved in loss of enterocyte polarity, tissue remodeling and cell motility; all functions likely to be involved in tumor invasiveness [3]. In the present cohort of patients only two of the human homologues from the murine gene list proposed were differentially expressed, i.e. plasminogen activator tissue (PLAT) and pancreatic lipase related protein 1 (PNLRP1) in tumors with impaired p53 function and low expression of CSNK1A1 versus the remaining tumors. The latter results might reflect differences between mouse and man. Moreover, the human comparison was not identical to the murine comparison by Elyada and co workers. Furthermore in contrast to the murine model, PLAT was upregulated in the group with at least one active gene (functional p53 with low or high CSNK1A1 expression and non functional p53 with high CSNK1A1 expression) and could therefore be associated with a better survival. In human, the increased expression of the plasminogen activator inhibitor was associated with the occurrence of distant metastasis in colon cancer [38], probably leading to decreased levels of PLAT which would corroborate our findings. To our knowledge, the role of PNLRP1 in tumor invasiveness and progression is so far unknown.

\section{Conclusion}

The combination of several approaches provides additional and accurate information on p53 status showing a detrimental effect on survival when p53 function is impaired. Nevertheless, gene interplay remains very important in tumor biology as it is illustrated by the modifying role of CSNK1A1 gene expression on the survival effects of TP53 in colon cancer. Loss of both genes confers an extremely poor prognosis to colon cancer patients.

\section{Additional file}

Additional file 1: Table S1. Call of p53 functionality according to all

parameters analyzed.

\section{Competing interest}

The authors have no conflict of interest to disclose.

\section{Authors' contributions}

All authors have contributed equally in the preparation and execution of this manuscript. AFS: data analysis, writing, allelic state assessment according to LAIR algorithm, FISH, p53 mutation analysis and immunohistochemistry scores. GIF: DNA isolation, cell sorting, manuscript review. WEC: allelic scores, cell sorting, manuscript review. NF dM: clinical follow up of the cohort, DNA isolation, immunohistochemistry, MSI determination, manuscript review. DR: allelic state score, statistical and array analysis, concept and manuscritp review. RvE: DNA isolation, p53 mutation and manuscript review. JO: Concept, LAIR algorithm development, statistics and manuscript review. RT: patient selection, concept and manuscript review. TvW: concept, DNA isolation, allelic state score and mnuscript review. HM: concept, analysis of histomorfology and immunohistochemistry scores and manuscript review. All authors read and approved the final manuscript. 


\section{Author details}

${ }^{1}$ Department of Pathology, Leiden University Medical Centre, P.O. Box 9600 L1-Q2300 RC, Leiden, the Netherlands. ²Department of Surgery, Leiden University Medical Centre, Leiden, the Netherlands.

Received: 1 November 2012 Accepted: 8 May 2013

Published: 5 June 2013

\section{References}

1. Cho KR, Vogelstein B: Genetic alterations in the adenoma-carcinoma sequence. Cancer 1992, 70(6 Suppl):1727-1731.

2. Bargonetti J, Manfredi JJ: Multiple roles of the tumor suppressor p53. Curr Opin Oncol 2002, 14(1):86-91.

3. Elyada E, Pribluda A, Goldstein RE, Morgenstern Y, Brachya G, Cojocaru G, Snir-Alkalay I, Burstain I, Haffner-Krausz R, Jung S, et al: CKlalpha ablation highlights a critical role for p53 in invasiveness control. Nature 2011, 470(7334):409-413.

4. Hollstein M, Sidransky D, Vogelstein B, Harris CC: p53 mutations in human cancers. Science 1991, 253:49-53.

5. Baretton GB, Vogt M, Muller C, Diebold J, Schneiderbanger K, Schmidt M Lohrs U: Prognostic significance of p53 expression, chromosome 17 copy number, and DNA ploidy in non-metastasized colorectal carcinomas (stages IB and II). Scand J Gastroenterol 1996, 31(5):481-489.

6. Bazan V, Migliavacca M, Zanna I, Tubiolo C, Corsale S, Calo V, Amato A Cammareri P, Latteri F, Grassi N, et al: DNA ploidy and S-phase fraction, but not p53 or NM23-H1 expression, predict outcome in colorectal cancer patients. Result of a 5-year prospective study. J Cancer Res Clin Oncol 2002, 128(12):650-658.

7. Bleeker WA, Hayes VM, Karrenbeld A, Hofstra RM, Hermans J, Buys CC, Plukker JT: Impact of KRAS and TP53 mutations on survival in patients with left- and right-sided Dukes' C colon cancer. Am J Gastroenterol 2000 95(10):2953-2957.

8. Bouzourene H, Gervaz P, Cerottini JP, Benhattar J, Chaubert P, Saraga E, Pampallona S, Bosman FT, Givel JC: p53 and Ki-ras as prognostic factors for Dukes' stage B colorectal cancer. Eur J Cancer 2000, 36(8):1008-1015.

9. Chang S-C, Lin J-K, Yang SH, Wang H-S, Li AF-Y, Chi C-W: Relationship between genetic alterations and prognosis in sporadic colorectal cancer. Int J Cancer 2006, 118:1721-1717.

10. Clausen $O P$, Lothe RA, Borresen-Dale AL, De Angelis $P$, Chen $Y$, Rognum TO, Meling Gl: Association of p53 accumulation with TP53 mutations, loss of heterozygosity at 17p13, and DNA ploidy status in 273 colorectal carcinomas. Diagn Mol Pathol 1998, 7(4):215-223.

11. Conlin A, Smith G, Carey FA, Wolf CR, Steele RJ: The prognostic significance of K-ras, p53, and APC mutations in colorectal carcinoma. Gut 2005, 54(9):1283-1286.

12. Elsaleh H, Powel B, McCaul K, Grieu F, Grant R, Joseph D, lacopetta B: p53 alteration and microsatellite instability have predictive value for survival benefit from chemotherapy in stage III colorectal carcinoma. Clin Cancer Res 2001, 7:1343-1349.

13. Goh H-S, Chan C-S, Khine K, Smith DR: p53 and the behaviour of colorectal cancer. Lancet 1994, 344:233-234.

14. Goh H-S, Yao J, Smith DR: p53 point mutation and survival in colorectal cancer patients. Cancer Res 1995, 55:5217-5221.

15. lacopetta B, Russo A, Bazan V, Dardanoni G, Gebbia N, Soussi T, Kerr D, Elsaleh $\mathrm{H}$, Soong R, Kandioler D, et al: Functional categories of TP53 mutation in colorectal cancer: results of an International Collaborative Study. Ann Oncol 2006, 17(5):842-847.

16. Munro AJ, Lain S, Lane DP: p53 abnormalities and outcomes in colorecta cancer:a systematic review. Br J Cancer 2005, 92:434-444.

17. Russo A, Bazan V, Agense V, Rodolico V, Gebbia N: Prognostic and predictive factors in colorectal cancer: Kirsten Ras in CRC (RASCAL) and TP53CRC collaborative studies. Ann Oncol 2005, 16(4):iv44-iv49.

18. Walther A, Houlston R, Tomlinson I: Association between chromosomal instability and prognosis in colorectal cancer: a meta-analysis. Gut 2008 , 57(7):941-950.

19. Westra $L$, Boven $L G$, van der Vlies P, Faber $H$, Sikkema B, Schaapveld M, Dijkhuizen T, Hollema H, Buys $\mathrm{CH}$, Plukker JT, et al: A substantial proportion of microsatellite-unstable colon tumors carry TP53 mutations while not showing chromosomal instability. Genes Chromosomes Cancer 2005, 43(2):194-201.
20. Venkatachalam S, Shi YP, Jones SN, Vogel H, Bradley A, Pinkel D, Donehower LA: Retention of wild-type $p 53$ in tumors from p53 heterozygous mice: reduction of p53 dosage can promote cancer formation. EMBO J 1998 17(16):4657-4667.

21. Lynch CJ, Milner J: Loss of one p53 allele results in four-fold reduction of p53 mRNA and protein: a basis for p53 haplo-insufficiency. Oncogene 2006, 25(24):3463-3470.

22. Yoon H, Liyanarachchi S, Wright FA, Davuluri R, Lockman JC, de la Chapelle A, Pellegata NS: Gene expression profiling of isogenic cells with different TP53 gene dosage reveals numerous genes that are affected by TP53 dosage and identifies CSPG2 as a direct target of p53. Proc Natl Acad Sci USA 2002, 99(24):15632-15637.

23. Corver WE, Middeldorp A, ter Haar NT, Jordanova ES, van Puijenbroek M van Eijk R, Cornelisse CJ, Fleuren GJ, Morreau H, Oosting J, et al: Genomewide allelic state analysis on flow-sorted tumor fractions provides an accurate measure of chromosomal aberrations. Cancer Res 2008 68(24):10333-10340.

24. Salazar R, Roepman P, Capella G, Moreno V, Simon I, Dreezen C, LopezDoriga A, Santos C, Marijnen C, Westerga J, et al: Gene Expression Signature to Improve Prognosis Prediction of Stage II and III Colorectal Cancer. J Clin Oncol 2011, 29(1):17-24.

25. Bosman F, Carneiro F, Hruban RH, Theise ND: WHO classification of tumours of the digestive system. Fourthth edition. Lyon, France: International Agency for Research on Cancer (IARC); 2010. Chapter 8; 134-146.

26. Corver WE, ter Haar NT: High-resolution multiparameter DNA flow cytometry for the detection and sorting of tumor and stromal subpopulations from paraffin-embedded tissues. Curr Protoc Cytom 2011, 7(7):37.

27. Corver WE, Ter Haar NT, Dreef EJ, Miranda NF, Prins FA, Jordanova ES, Cornelisse CJ, Fleuren GJ: High-resolution multi-parameter DNA flow cytometry enables detection of tumour and stromal cell subpopulations in paraffin-embedded tissues. J Pathol 2005, 206(2):233-241.

28. Lips EH, van Eijk R, de Graaf EJ, Doornebosch PG, de Miranda NF, Oosting J, Karsten T, Eilers PH, Tollenaar RA, van Wezel T, et al: Progression and tumor heterogeneity analysis in early rectal cancer. Clin Cancer Res 2008, 14(3):772-781

29. Middeldorp A, van Eijk R, Oosting J, Forte Gl, van Puijenbroek M, van Nieuwenhuizen M, Corver WE, Ruano D, Caldes T, Wijnen J, et al: Increased frequency of $20 q$ gain and copy-neutral loss of heterozygosity in mismatch repair proficient familial colorectal carcinomas. Int J Cancer 2011.

30. Cruz I, Snijders PJ, Van Houten V, Vosjan M, Van der Waal I, Meijer CJ: Specific p53 immunostaining patterns are associated with smoking habits in patients with oral squamous cell carcinomas. J Clin Pathol 2002, 55(11):834-840.

31. Romeo S, Debiec-Rychter M, Van Glabbeke M, Van Paassen H, Comite P, Van Eijk R, Oosting J, Verweij J, Terrier P, Schneider U, et al: Cell cycle/apoptosis molecule expression correlates with imatinib response in patients with advanced gastrointestinal stromal tumors. Clin Cancer Res 2009, 15(12):4191-4198.

32. Hosmer DW, Lemeshow S: Applied survival analysis. Regression modelling of time to event data. New York: John Wiley \& Sons, INC; 1999.

33. Smyth GK: Linear models and empirical bayes methods for assessing differential expression in microarray experiments. Stat Appl Genet Mol Biol 2004, 3:3.

34. Vousden $\mathrm{KH}$, Lane DP: p53 in health and disease. Nat Rev Mol Cell Biol 2007, 8(4):275-283

35. Vousden $\mathrm{KH}$, Prives $\mathrm{C}$ : Blinded by the Light: The Growing Complexity of p53. Cell 2009, 137(3):413-431.

36. Zuckerman V, Wolyniec K, Sionov RV, Haupt S, Haupt Y: Tumour suppression by $\mathrm{p} 53$ : the importance of apoptosis and cellular senescence. J Pathol 2009, 219(1):3-15.

37. Liu C, Li Y, Semenov M, Han C, Baeg GH, Tan Y, Zhang Z, Lin X, He X: Control of beta-catenin phosphorylation/degradation by a dual-kinase mechanism. Cell 2002, 108(6):837-847.

38. Markl B, Renk I, Oruzio DV, Jahnig H, Schenkirsch G, Scholer C, Ehret W Arnholdt HM, Anthuber M, Spatz H: Tumour budding, uPA and PAl-1 are associated with aggressive behaviour in colon cancer. J Surg Oncol 2010 102(3):235-241.

doi:10.1186/1471-2407-13-277

Cite this article as: Fariña Sarasqueta et al:: Integral analysis of p53 and its value as prognostic factor in sporadic colon cancer. BMC Cancer 2013 $13: 277$. 